\title{
A critical feminist discursive analysis of dynamics shaping abortion in Canada: Implications for nursing.
}

\author{
Margaret Lebold RN MScN \& Judith A. MacDonnell RN PhD \\ York University, School of Nursing, 4700 Keele Street, Toronto, Ontario, Canada.
}

Cite as: Lebold, M. \& MacDonnell, J. A. (2020). A critical feminist discursive analysis of dynamics shaping abortion in Canada: Implications for nursing. Witness: The Canadian Journal of Critical Nursing Discourse, Vol 2(2), pp 76-91. https://doi.10.25071/2291-5796.76

\begin{abstract}
The advent of "the abortion pill" (Mifegymiso) in 2015 has shaped the contemporary context of access to abortion in Canada. In this paper, we highlight findings of a literature review that uses a gender and intersectional lens and critical discourse analysis to explore contemporary abortion access and implications for nursing. The discursive dynamics influencing nurses' understandings of abortion, that is, the contexts in which some discourses are privileged over others yet often operate at the unconscious level to influence everyday knowledge and practices, are important to discern to work towards social justice goals. Findings suggest that normative and contradictory features of discourses such as women's health, motherhood, and abortion access are relevant. Given the relative silence of abortion in nursing literature and prevailing gender normativity in nursing, there are compelling reasons to apply a critical feminist lens to deepen nurses' understandings and critical reflection about abortion. There are implications for current education, research, and nursing practice.
\end{abstract}

Keywords: abortion access, critical feminist, motherhood, critical discourses, Mifegymiso, literature review

This is a pivotal time in the history of women's health in Canada with the advent of "the abortion pill" (Mifegymiso) in 2015. Reproductive health, including access to abortion, are well documented as relevant to women's health in a Canadian context (Greaves $\&$ Whynot, 2014). Although abortion rights are protected in Canada, abortion access continues to be contested (Saurette \& Gordon, 2015).
Nurses are ethically mandated to support the holistic health of diverse individuals and communities (Canadian Nurses Association, 2017). With the arrival of the abortion pill the landscape of abortion in Canada has changed, ostensibly making abortion more accessible in Canada. It seemed important and timely, therefore, to examine the literature to better understand the broad and contextual dynamics

Corresponding Author: Margaret Lebold, PhD Student, York University, School of Nursing, 4700 Keele

Street, Toronto, Ontario, Canada mlebold@yorku.ca 
shaping contemporary abortion access in Canada and implications for nursing. In undertaking the literature review, we gathered a range of perspectives, including international and interdisciplinary research; however, for the purpose of the critical discourse analysis we focused mainly on the contemporary Canadian context and drew upon some American policy literature.

In Canada, where abortion rights have been achieved since 1988, and the abortion debate "closed", there is however, recent evidence and media awareness of attempts to erode Canadian women's sexual and reproductive rights. For example, in May 2019 in Ontario, three Members of Provincial Parliament (MPPs) spoke at an anti-abortion rally and vowed "to make abortion unthinkable in [their] lifetime" (Clementson, 2019). During the COVID-19 pandemic, fears about abortion access heightened and concern arose across North America, about whether governments would consider abortion an essential service during the pandemic, or whether pregnant people would be forced to maintain unwanted pregnancies (Action Canada for Sexual Health and Rights, 2020; Peters, 2020).

Successful and tireless work by advocates set the foundation for increasing abortion accessibility in Canada in the latter half of the current decade (Stettner, 2016a). Given Canada's vast geography, along with mounting evidence from other countries that medical abortion could assist more people who need abortions gain physical access, a major focus of abortion-related research in recent years (2015present) was connected with advocacy efforts to access the long-awaited "gold-standard" abortion pill: mifepristone/misoprostol, known as "Mifegymiso" in Canada (CBC News, 2019; Winikoff \& Sheldon, 2012). This abortion pill was first made available in France and China in the 1980s, and proved to be a discreet method of abortion, allowing women to gain access to abortions without necessitating surgical facilities (Winikoff \& Sheldon, 2012). Many abortion advocates pushed for access to mifepristone for years, but, due to the lengthy and costly medication approval process in Canada, combined with the country's relatively small population size, Mifegymiso's submission to Health Canada took many years to materialize, finally being approved in 2015, with initial distribution commencing in 2017 (CBC News, 2019; Winnikoff \& Sheldon, 2012). Since 2019, Mifegymiso is now available in at least one part of each province/territory, although individual ease of access still varies significantly ${ }^{1}$ (Action Canada for Sexual Health and Rights, 2019a; CBC News, 2019). This is not to say that procuring Mifegymiso for people who need abortion is now simple. In fact, medical oversight remains common pre- and postabortion, although, guidelines around the necessity of ultrasounds pre-abortion have recently become more flexible (National Abortion Federation, 2020).

By applying a critical feminist lens in this literature review about abortion in the contemporary context, we uncover contradictions and challenges to commonly held assumptions about abortion, and counterdiscourses to dominant discourses that shape the contemporary abortion context in Canada. In doing so, we illustrate the value of a critical feminist lens in generating complex understandings about discursive dynamics (i.e., dominant and non-dominant discourses shaping abortion) that are needed for nurses. The discursive dynamics influencing our understanding of abortion, that is, the contexts in which some discourses are privileged over others, yet often operate at the unconscious level to influence our everyday knowledge and practices, are important to discern to work towards social justice goals. We suggest that such complex understandings of discursive dynamics are important to discern, for example, how some dominant discourses prevail while

\footnotetext{
${ }^{1}$ Access was also facilitated by the parallel removal of previously mandatory pre-abortion ultrasound requirement that advocates claimed was sometimes nearly equally difficult to obtain as abortion, particularly in rural and Northern Canadian communities (Zingel, 2019).
} 
others are marginalized, and how these have impacts for what knowledge is available.

\section{Methodology: Critical Feminist and Intersectional Lens}

The purpose of this literature review was to identify dynamics including normative discourses that influence contemporary access to abortion in Canada with a goal of understanding implications for nursing. To do so, we purposely take a broad and critical scope when exploring access, expanding the confines of more typical nursing and health services abortion research to draw from literature in nursing, women's studies, and social sciences.

We use a critical feminist and intersectional lens (Kagan et al., 2010) to examine social, political, economic, cultural, and historical forces, including dominant discourses about women's health, motherhood, and abortion access that shape abortion. Like Kagan et al. (2010), we draw from critical social theory to apply our critical feminist worldview that recognizes that knowledge is "created within a socio-political context and shaped by power dynamics" and "values subjugated ways of being and knowing" (p. 69). Our priorities are to affirm multiple ways of knowing and amplify traditionally silenced ways of knowing, towards awareness and action-oriented material changes (Kagan et al., 2010, 2014). We take a feminist approach that assumes that gender matters, that knowledge is constructed, and that knowledge is gendered (Hankivsky, 2007). Our position is that gender and gendered social dynamics operate and have meaning in the lives of people who have abortions. Our approach also uses an "intersectional theory [that] posits that gender is distinct from but interacts with other social features like social class or race/ethnicity such that their effects are mutually constitutive rather than separate" (Pederson et al., 2014, p. 28).

Critical discourse analysis focuses on ways of knowing that are privileged or marginalized in particular contexts and examines how discourses reinforce power structures and underlying inequalities (Fairclough, 1995; Smith 2007). Critical discourse analysis can rupture otherwise taken for granted discourses, by showing how there is a link between language and social practices and the ways knowledge is regulated (Fairclough, 1995). We foreground gender identities and make visible how what we understand of abortion is constructed through gendered discourses. While we centralize gender in this literature review, we also think about how additional "axes of difference" or intersectionalities, such as class, race, and sexuality (Hankivsky, 2007) are relevant to the lives of diverse people who have abortion. We also pay attention to how diverse, intersectional abortion discourses and the experiences they represent are eclipsed by dominant ways of knowing.

At any time, there are many discourses circulating and embedded in texts such as the literature reviewed here. These discourses are always contextualized by shifting historical, political, economic, social, and cultural dynamics such that any analysis is necessarily partial (Lazar, 2007). Thus, we identify our approach to apply a gender and intersectional lens and point to selected discourses for the purposes of this analysis and how they operate and relate to one another and with what impacts. We note that the available literature is broad but limited with respect to nursing research, especially in a Canadian context. Our analysis offers insight into the Canadian context, but we recognize that there may be particular impacts for diverse people across Canada in relation to the impacts of these discursive dynamics on abortion access and in relation to nursing practice. The key is that these dominant and counter dynamics are potentially in play in all contexts in which nurses practise and in which abortion access is enabled or restricted for individuals or groups. Our analysis points to the need to illuminate these dynamics.

Critical feminist discourse is a specific area of critical discourse analysis that is "guided by feminist principles and insights in theorising and analysing the seemingly innocuous yet 
oppressive nature of gender as an omni-relevant category in many social practices" (Lazar, 2007, p. 143). Critical feminist discourse analysis is particularly useful in identifying the subtle, contemporary, and often taken-for-granted ways in which gender assumptions and power dynamics are discursively enacted (Lazar, 2007). Although a critical feminist discourse analysis can be critiqued for being too abstract, it is a methodology that moves us in an emancipatory direction (Lazar, 2007). It is a move away from the descriptive exploration of texts, to critical ones that focus on subtleties embedded in contemporary discourses (Smith, 2007). It is in critical feminist discourse that we find opportunity for reflection and consideration about abortion discourse.

Four gendered discourses (women's health, motherhood, access, and nursing) emerged for us as relevant through a critical review of the literature on abortion access and were chosen for the purpose of this analysis. We began with a critical feminist analysis and as we identified discourses, we determined that a critical discourse analysis was helpful. We selected these discourses through an iterative, reflexive and recursive process of discussion in which we examined the forces shaping understandings (Lazar, 2007; Smith, 2007) of abortion access beyond the taken for granted challenges associated with abortion access. The discourses about abortion from the critical literature pointed to contradictions and counter discourses, especially when we looked at these in relation to each other through critical feminist and intersectional lenses. We juxtaposed dominant and nondominant abortion discourses that we found in the literature in order to better understand how particular discourses operate and dominate and to illuminate alternative, more inclusive discourses through this critical feminist and intersectional lens. To do so, we explored some of the limitations of these normative discourses and illuminated more inclusive ones. We asked: What are the normative discourses about abortion and implications for nursing? Looking at nondominant ways of knowing and drawing out underrepresented perspectives (Kagan et al., 2010), we looked at how challenging dominant gender norms can disrupt our assumptions and understanding of abortion (MacDonnell, 2014).

Angie Deveau's own abortion story offers such a disruption to common discourses about motherhood. She shares:

... I will always have a "what if" in the back of my head. Honestly, I think the "what if" feeling is less my romanticizing the notion of having another child and more my imagining my life and emotions spiraling even further out of control (Deveau, 2017, p. 44).

Deveau's story takes a feminist-mothering, or, matricentric form (Green, 2018), centralizing her personal wellbeing in a way that differs from common public abortion discourses centered around abortion rights. As Angie's story demonstrates, to understand, we need to have more complex and intersectional renderings of understanding of abortion.

\section{Interrogating the Notion of Abortion as a Women's Health Issue}

Reported abortions over the last few years suggest that 100,000 abortions take place each year in Canada ${ }^{2}$ (CIHI, 2017), and while Canadian contexts are central in this paper, we recognize that this does not comprehensively reflect the experiences of people globally. Worldwide, $45 \%$ of all abortions are considered unsafe, and these abortions are known to happen largely in countries where women have few abortion rights (Ganatra et al., 2017; World Health Organization (WHO), 2018). Attitudes about abortion and access vary significantly across the world, including some countries

\footnotetext{
${ }^{2}$ Approximately 85,000 abortions were reported in Canada in 2018, however, given variable reporting requirements, abortion data may not adequately capture or approximate the total number of medical and surgical abortions completed in Canada (CIHI, 2018).
} 
where abortion is either less or more normalized than in Canada (Purcell, 2015).

Critical feminist perspectives examine the social, political, economic, cultural, and historical aspects of a given situation. They consider the ways in which people are situated diversely, based on social factors, and how systems and structures of power, laws, and policies reinforce long-held positions of oppression and privilege (Hankivsky, 2020). In our review, it was evident that much of the current abortion literature has a critical spin and reflects both challenges and progress for women locally and globally. The commonly described material and social impacts of abortion are indeed critical (for example, the financial, social, and navigation aspects of abortion). The fact that these impacts are even known is a product of women's research and women's advocacy (Begnell \& Durey, 2014). Thinking broadly about contexts, gender, power, and intersectionality, we aim to understand the contemporary experiences of people needing abortion more fully by turning to the social, legal, and critical literature, and by exploring implications for nursing.

It must be noted upfront, that a persistent gap remains in our ability to understand diversely situated people who have abortions in Canada. Noticeably, the experiences of people who have abortions still largely represent the experiences of a non-diverse racial/ethnic (i.e., White) and gender groups (i.e., cisgender women). However, there is evidence of more recent inclusion of some increased racial/ethnic diversities (Cano \& Foster, 2016; Foster et al., 2017; Mitchell, 2019; Vogel et al., 2016) and some attention to Muslim women's experiences (Wiebe et al., 2011) in the recent Canadian abortion literature.

Historically, abortion has fallen under the rubric of "women's health." Notwithstanding robust recent clinical guidance for transinclusive abortion care (Lowik, 2018), research exploring the abortion experiences of transgender and non-binary folks remains critically needed (Mitchell, 2019). As well, the cis-normative construction of mutually exclusive gender binary categories (male/female) continue to pervade the literature on abortion, for example, "women who have abortions." However, recognizing that people of various genders may require abortions, Lowik (2018) implores clinicians to use more inclusive language; language such as: "anyone experiencing an unplanned or unexpected pregnancy", "pregnant people", and "people who have abortions."

At the same time, it is relevant to recognize both the historical abortion advocacy work taken on by many cisgender women, and that cisgender women are the single-most likely gender group to necessitate abortions. In this paper, therefore, drawing from Ross and Solinger (2017) and similar to Mitchell (2019), we use women who have abortions when talking about historical references and events or referencing others' work who talk specifically about women. When referring to contemporary groups of people who have abortions we strive to use people who have abortions and language suggested by Lowik (2018).

\section{Juxtaposing Abortion Language and Motherhood}

Examining varied conceptualizations of motherhood can inform a deeper understanding of abortion. Abortions are often framed as being "resistance" to a traditional pronatalist view of motherhood aligned with a White, middle-class, heteronormative, nuclear family model in which a "real woman" bears children (DiLapi, 1989; Green, 2019; Jones et al., 2008). Women who choose abortion are deemed to be "abandoning" their fertility and femininity (Abrams, 2015). Such normative views, aligned with the "institution of motherhood" (Green, 2019; O'Reilly, 2004) are embedded in all social institutions such as the health and legal systems such that women are often stigmatized, and in many instances outside of Canada, abortion remains illegal (Abrams, 2015). Women who challenge motherhood ideologies based on 
maintaining patriarchal authority over women's lives can self define motherhood and what it means to be a "good mother" (Green, 2018; MacDonnell, 2006).

A range of mothering practices shift dominant motherhood ideas and are instead aligned with feminist mothering practices, for example, through resisting imposed expectations of motherhood, such as self-sacrificing behaviour (Green, 2018). The few studies that explore mothers' experiences with abortion suggest that women considered their abortion decisions in relation to relationship concerns, including abuse, and delayed motherhood until they could raise children in healthy relationships and/or prioritized their conditions and those of their existing children (Jones et al., 2008; Wiebe et al., 2012).

Contradictions about motherhood persist as women across social locations often face poor conditions for mothering. Even as traditional motherhood is lauded as the desirable social job of women in a traditional context, it is often devalued. It is unpaid work and there are limited resources and supports for mothers to raise children, including family-hostile work environments with even fewer resources available to those raising children on the margins (Bogart \& Lee, 2020; DiLapi, 1989; Medoff, 2016; Rippeyoung, 2013).

Coincidingly, anti-abortion discourses are at the centre of the reinforcement of traditional views of femininity and sexuality. Discourses about who is fit to be a mother have long persisted, often with consequences for those who mother despite being seen as unfit to mother, and similarly for those who are seen as fit to mother but who choose not to (Bourgeois, 2014). These gendered discourses of motherhood and femininity work to limit access to abortion (Bourgeois, 2014). Reinforced messages about femininity and motherhood also have implications for trans-men and non-binary people who have been long excluded from conversations about both abortion and parenting, reflecting narrow and persisting conceptualizations of gender, reproduction, and family (Lowik, 2018).

\section{Access to Surgical and Medical Abortion}

In our view, what is typically known about abortions among health care providers, are the many barriers people face to obtaining an abortion; in other words, "physical access." In Canada, these barriers are namely the noticeable geographic barriers and the associated materials and impacts, such as those required to travel to see an abortion provider-e.g., related costs such as: travel/gas, hotel, childcare, lost work time-all of which are particularly pronounced among young women of low socioeconomic status (Cano \& Foster, 2016; Sethna \& Doull, 2013). People living in rural settings have longfaced, and continue to face, the impacts of significant systemic challenges to abortion access, including inadequate health care staffing and provider unwillingness to perform/provide abortion care (Action Canada for Sexual Health and Rights, 2019a, Cano \& Foster, 2016; Dressler et al., 2013; Norman et al., 2013).

A critical feminist perspective illuminates the contexts of abortion access: how people come to experience abortion access is about how they navigate the social, familial, community, and political contexts unique to them - and equally, how individuals, situated differently, have resisted such contexts. Thus, abortion access can also be about agency and structures of control permitting — or denyingagency. It is important to acknowledge that women have been controlling their bodies since time immemorial, and women have found ways to have abortions even when officially restricted (Boston Women's Health Book Collective, 2011; Ehrenreich \& English, 1973/2010). The advent and accessibility of the abortion pill is radical in that it allows for autonomous selfadministration and at-home abortion, rejecting the contemporary and dominant biomedical ways in which abortion was once, up until very recently, only accessible through direct provider intervention (for example, vacuum aspiration abortions in clinic or hospital settings) (Paynter 
et al., 2019).

Even today, licensed providers largely remain gatekeepers to traditional, safe, abortion access - necessitating that providers examine issues of power in their relationships with people seeking abortion care (Paynter et al., 2019) however, the gendered dynamics, such as those described by McPherson (2003), may prevail in nurses' unexamined assumptions about their values and practices (MacDonnell, 2014). Additionally, nursing has a history that is gendered and has operated in traditional power hierarchies. Scholars who have studied nursing have noted that the profession maintains gendered normativity, and where nursing may still adhere to historical roles as passive, complacent and "do-gooders" (McPherson, 2003; Traynor, 2017). Gendered discourses shape professionalism, respectability, and authority as McPherson (2003) has suggested.

\section{Impacts of Normative Discourses that Shape Abortion}

Discourses form norms and are often used to maintain the status quo of power and control among dominant groups, and without critique, often reinforce binaries (Daley \& MacDonnell, 2011). Used to ultimately influence political outcomes, discourses work by shaping and persuading audiences of, for example, select sets of values, "appropriate" emotional responses, and ideologies (Saurette \& Gordon, 2015). The more normalized and commonplace discourses are, the more likely they are to become imbedded in policy which health care providers may reaffirm, for example, through the common pathologization of certain groups of people (Saurette \& Gordon, 2015). Given their status as minority gender groups, women and non-binary people are no strangers to the many everyday discourses that attempt to control their behaviours and beliefs.

Historically, the most visible antiabortion discourses occurred in public, at abortion protests whereby anti-abortion language was often used with intensity - toward women on their way to have an abortion. In recognition of these verbal (and sometimes physical) threats at abortion clinics, many provinces have now enacted "bubble zones" thus restricting protesting around clinics (Bellefontaine, 2018; CBC News, 2018). However, despite the restrictions imposed on abortion protesting and the bubble zones enacted, anti-abortion discourses have increasingly found ways into more public spaces - for example, on university campuses, on advertising space on public transit buses, and in online environments (Eaton, 2018; Endemann, 2019; Mallick, 2017; Saurette \& Gordon, 2015). This demonstrates the ways in which broad and far-reaching public and online spaces are being sought to convey anti-abortion dialogue as policies change and technologies evolve.

Meanwhile, spaces exist where frank abortion discourse is omitted. The omission of the term abortion from Ontario's current (and all preceding) sexual health curriculums is evidence of such an omission (Action Canada for Sexual Health and Rights, 2019b). Likewise, the omission of abortion education and training in nursing and medicine has received recent attention (Paynter et al., 2019). Yet, by pointing out the gaps, opportunities to challenge such silences are also made visible and may compel us to action (Paynter et al., 2019; Saurette \& Gordon, 2015).

The way abortion discourses are framed and discussed has much to say about how people understand abortion, their rights, and needs. Many discourses are subliminal, and it takes a lens of marginalization to illuminate how these normative discourses are enacted and the implications of such discourses. A discourse analysis performed by Saurette and Gordon (2013) on anti-abortion dialogue in Canada found that abortion language has shifted over the course of the past 40 years - taking on more "pro-woman"/pro-feminist similarities in order to appeal to, and perhaps to conceal, anti- 
abortion sentiments in similarly-worded, but differently-intentioned terms. For example, "pro-family" and "women's care clinics" are terms commonly used among common-day anti-abortion agencies (Ibrahim, 2018; Saurette \& Gordon, 2013). Yet, even in traditional caring spaces of nursing, the ways abortions are commonly discussed can also be critiqued.

Discourses often reflect the maintenance of structural powers that represent the state's interests, and are often enacted by self-regulated health care providers where there is a sense they have authority to decide what is best, even if it may undermine people's own knowledge and agency. In the contemporary context, discourses such as abortions should be rare still perpetuate, and can imply that abortions are occurring more often than they should, creating false goals or misguided priorities for providers to reduce abortion rates, or to accept abortions on conditional bases, instead of improving access to abortions (Stettner, 2016b; Weitz, 2010).

Working closely beside medicine, while nurses have resisted, they have often upheld gatekeeping and decision-making powers at different points over time, reinforcing overtones of middle-class values, often undermining people's own agency and knowledge (Kagan et al., 2014; McPherson, 2003). Such impositions, including ideas as abortions should be rare, can operate in ways that restrict which people are seen as fit to have children, for example, enacting social and political discourses to ensure low abortion rates. The result is often discourses that promote certain "acceptable" forms of birth control much more widely and openly than other available options (Carson, 2018). And, although the advent of the abortion pill in Canada represents a turn towards abortion selfmanagement versus control, (Paynter et al., 2019), reproductive gatekeeping and control continue (Mitchell, 2019).

Both health care providers and those in larger society are immersed in broader social discourses and are likely to subscribe to many such discourses, because they dominate. Furthermore, nurses represent these social norms, and nursing is a site where norms are enacted (McPherson, 2003). People in nondominant positions can often internalize dominant discourses, which can in turn, affect self-blame and decision-making. The phrase the medical necessity of abortion, is an example of a phrase reflecting social norms in health care that can serve to reinforce structures of power and privilege and eclipse underlying structures of oppression. A persistent focus on the medical necessity of abortion, draws attention to the medical aspect of abortion, while excluding the social, economic, and personal, gendered, and intersectional necessities of abortion (Kaposy, 2009). Such discourses have been critiqued for centering biomedical access-focused solutions, to the exclusion of long-term outcomes for health and wellbeing. This is not to say that access to abortion is never medically necessary, but rather that greater attention ought to be paid to the social necessities of abortion, for example - the structural realities and challenges of childrearing today - and why and how these structures are reinforced. Medoff's (2016) research implies the importance of connecting maternal health with reproductive health and exploring these issues together ${ }^{3}$. Employing discourses that focus on the social necessity of abortion, expands attention to abortion beyond a medical need (Kaposy, 2009; Medoff, 2016).

Nurses themselves, are immersed in a gendered profession and within it discourses of passivity and powerlessness often circulate (Traynor, 2017). Historically, nurses could not be married, could not be lesbian, and ought to be "proper" women, able to follow directions provided by male superiors, and always "nice rather than clever" (McPherson, 2003; Traynor, 2017 , p. 81). Historically, nursing was a profession for women, and remains to this day, a profession taken up largely by cisgender women (Traynor, 2017). With this, there is an expectation that nurses will uphold traditional

\footnotetext{
${ }^{3}$ This is related to the broader concept of reproductive justice, explored in detail elsewhere (see: Ross \& Solinger, 2017).
} 
feminine morality and shy away from stigmatized topics, to thereby maintain their "maternal" position relative to the patient, and as part of the doctor-nurse "parental team" (McPherson, 2003). Paynter et al. (2019) describe the ways in which physicians, who, until recently, held exclusive authority to perform abortions, often obscured nursing's significant contribution in the provision of abortion care.

From this frame of reference of nurses as upholders of middleclass assumptions of values and morality, we explore two other terms common in abortion discourse: elective abortion and choice. Although the term elective abortion is common, from a critical feminist perspective is misleading (Lippman, 2014). To many people, abortions are not generally considered elective but rather necessary, by people who are unexpectedly pregnant, for any number of social, economic, or cultural reasons (Lippman, 2014). In other words, many people's diverse positions - or intersectionalities - make abortions a non-negotiable necessity. The term elective abortion has the effect of suggestingperhaps imposing - that high levels of social privilege are available to all people; that all people, without pause, could have a child, when, this more accurately reflects a decontextualized understanding of people's, and especially mothers' roles and responsibilities. For example, women often express current life scenarios that necessitate their need for an abortion, for example, to care for children, to attend to school or work priorities, or to care for family crises (Janiak \& Goldberg, 2016). It is key to note too, that some women have been denied elective childbearing - indeed, women in Canada have been forced to have abortions (e.g., Indigenous women), raising questions about who exactly gets to define abortion as "elective" (Boyer \& Bartlett, 2017).

In a comparable way, discourses that focus on abortion as a choice, although often used in a choice-as-good (e.g., "client choice"), can reinforce gendered messages and the maintenance of structures of power and control. Saurette and Gordon (2015) write about women who have faced scrutiny for having an abortion because they are wrongly perceived to have choice, when in fact, they may have little viable choice available. For example, discourses that criticize abortion for reasons due to sex selection and fetal anomaly can place further limitations and guilt on women who already live in tremendously sexist and ableist social networks (Vogel, 2012). For this reason, abortion advocates suggest that all abortions need to be valid - that women do not deserve additional intense scrutiny in their lives in addition to the possible ongoing oppressions they face everyday, a truth with particular salience for women of colour and marginalized women who may face disproportional social pressures to have abortions, and who would likely receive unreasonably more scrutiny from such a ban (Vogel, 2012). Yet, dialogue about banning sex selection is vast, and even medical doctors have written about their hopes that inequality found in sex selection abortion studies will be used to develop policies "aimed at eliminating the practice of prenatal sex selection in Canada" (Yasseen III \& Lacaze-Masmonteil, 2016, p. 640). It is important to realize that sex selection bans would do little to eliminate the root causes and perpetuation of sexist and gender-biased social norms that work to promote the maintenance of one gender over another (Vogel, 2012). In a similar way, it is relevant to consider the many socioeconomic realities of people's lives, and that proceeding with a pregnancy with a known fetal anomaly may be considered the right choice for some, while for others, abortion may be the necessary choice. Much depends on varying pre-existing oppressions and barriers, or supports and privileges, in people's lives. A feminist approach accepts the limitations of choices, and thereby centralizes personal and subjective reproductive decisions (Saurette \& Gordon, 2015).

\section{Implications for Nurses}

In this paper, we have shown how reflection and careful attention to the value of a critical and intersectional lens renders complex understandings of abortion that are valuable for 
contemporary nursing. Reflection is warranted about how nursing is implicated in motherhood, abortion discourses, and abortion access in everyday practice, research, and education. Nursing itself is situated in historical and gendered underpinnings that continue to have impacts to nursing practice today, for example, through heteronormative tendencies, nurses, as well as all people who are working in relation to discourses, may internalize dominant discourses, not necessarily having spent time to understand the complexities of abortion access.

Taking nursing into consideration, we show contradictions that exist in our own field; and highlight dominant discourses and silences through exemplars, to build an understanding about how abortion discourses and silences take shape in nursing, and how these may influence care. In sharing this literature, and writing about abortion in nursing, we are indeed contradicting normative discourses and resultant silences that can operate in nursing and show how a critical feminist lens can help illuminate these.

Therefore, we suggest that abortion discourseswhether subtle or not-have implications for nursing. We present literature that exemplifies how discourses work and may influence the ways in which nurses interact with patients who have abortions; how these discourses affect the ways in which abortion is presented and taught in nursing school (Paynter et al., 2019); and the extent to which abortion research is explored in nursing.

We find there remains a stigma about doing research at the intersection of nursing, mothering, and abortion. To share this kind of knowledge in nursing is a contradiction to the traditionally conceptualized role of the nurse. The consequence is, of course, that the operation of normative discourses of motherhood and abortion remain largely understudied in nursing. There is a need to set the context for where nursing and abortion intersect and we would suggest there are implications across many domains of nursing - for example, normative practices about what is taught and what is not in nursing education and what topic areas are made visible and which are overshadowed in nursing discourses about nursing activism for policy change. These findings support the call made by Paynter et al. (2019) for the inclusion of abortion curriculum, along with opportunities for nursing students to participate in abortion care, and provide opportunities for deep reflection on the assumptions and knowledges that we take for granted. Together, this critical discourse analysis and Paynter et al. (2019) can be read as openings towards more visible and emancipatory abortion advocacy by nurses (Begnell \& Durey, 2014). It fits well within other calls for emancipatory nursing research practice and education (Kagan et al., 2010, 2014; MacDonnell, 2014).

\section{Conclusion}

In this review, using a critical feminist perspective, we have highlighted some ways interdisciplinary abortion literature disrupts and challenges several of the normative ways of thinking about abortion. We first looked at women's health and raised questions about inclusivity and taken for granted discourses and assumptions about motherhood. By looking at women's health in relation to abortion, we uncovered the need to disrupt the discourse of women's health in favour of a more inclusive rendering, in which people - not just womenhave abortions. Then, we looked at gender in relation to abortion access and discourses to uncover several limitations of abortion in contemporary Canadian nursing contexts, shedding light on the gendered dynamics, the history of the profession, and the silences in nursing.

Although there is some nursing literature examining abortion, recent nursing literature draws attention to the enhanced educational opportunities to study abortion and for increased participation of nurses as primary providers in abortion provision (Paynter et al., 2019). Little is known in the current Canadian nursing literature about the experiences of people who have abortions, although earlier nursing research found that women's 
experiences with abortion are complex and contextual, influenced by, among other factors, social discourses about abortion and mothering (McIntryre et al., 2001). Our analysis builds on McIntyre et al. (2001) and Paynter et al. (2019) and suggests attention to both dominant and counter-dominant discourses and gender roles of nurses deepens abortion scholarship. In this context, there is a need for more nursing research using a critical feminist lens and critical discourse analysis to better understand the particular ways that discourses impact abortion access for diverse groups - including research focused on the experiences of Black, Indigenous, and People of Colour and gender diverse people. In tandem, we argue for a continued application of critical feminist perspectives in education to deepen nurses' reflection and understandings and appreciation of the socially dynamic, gendered, and intersectional experiences of people who have abortion. How people understand and make meaning of abortion in the context of their lives amidst the discourses that shape contemporary abortion has implications for all people and nurses who support them.

\section{Ethical Permissions}

Ethical permissions from York University's Ethics Review Board were provided for ML's MScN thesis (STU 2017-165).

\section{Acknowledgements}

I (ML) would like to thank the Canadian Nurses Foundation for providing support for my $\mathrm{MScN}$ thesis through the Agnes Campbell Neill scholarship (2017-2018). 
The Canadian Journal of Critical Nursing Discourse

See it. Speak it. Write it. Change it.

\section{References}

Abrams, P. (2015). The bad mother: Stigma, abortion and surrogacy. Journal of Law, Medicine, \& Ethics, Summer, 179-191. https://doi.org/10.1111/jlme.12231

Action Canada for Sexual Health and Rights. (2019a). Access at a glance: Abortion services in Canada.

https://www.actioncanadashr.org/resource s/factsheets-guidelines/2019-09-19access-glance-abortion-services-canada

Action Canada for Sexual Health and Rights. (2019b). Statement on Ontario's sex-ed curriculum.

https://www.actioncanadashr.org/news/20 19-03-19statement-ontarios-sex-edcurriculum

Action Canada for Sexual Health and Rights. (2020). Joint statement on essential abortion care during COVID-19. https://www.actioncanadashr.org/news/20 20-03-20-joint-statement-essentialabortion-care-during-covid-19

Bellefontaine, M. (2018, April 4). Alberta to introduce 'safe zones' around abortion clinics. CBC News.

https://www.cbc.ca/news/canada/edmonto n/alberta-to-introducesafe-zones-aroundabortion-clinics-1.4605302

Begnell, P. \& Durey, R. (2014). Creating lasting change: Advocacy for gendertransformative health promotion. In L. Greaves, A. Pederson, \& N. Poole (Eds.), Making it better: Gender transformative health promotion (pp. 212-224). Canadian Scholars' Press/Women's Press.

Bogart, N. \& Lee, V. (2020, May 18). Child care restrictions preventing some from going back to work as economy reopens. CTV News.

https://www.ctvnews.ca/health/coronaviru s/child-care-restrictions-preventing-somefrom-going-back-to-work-as-economyreopens- 1.4944380
Boston Women's Health Book Collective. (2011). Our bodies, ourselves (Rev. ed.). Simon \& Schuster.

https://www.ourbodiesourselves.org/publi cations/our-bodies-ourselves-2011/

Bourgeois, S. (2014). Our bodies are our own: connecting abortion and social policy. Canadian Review of Social Policy, 70, 2233.

https://crsp.journals.yorku.ca/index.php/cr sp/article/view/38700/35108

Boyer, Y. \& Bartlett, J. (2017). External review: Tubal ligation in the Saskatoon Health Region: The lived experience of Aboriginal women. https://www.saskatoonhealthregion.ca/Do cumentsInternal/Tubal_Ligation_intheSas katoonHealthRegion the Lived Experien ce_of_Aboriginal_Women_BoyerandBart lett_July_22_2017.pdf

Canadian Institute for Health Information (CIHI). (2017). Induced abortion reported in Canada in 2017 [Data set].

https://www.cihi.ca/en/induced-abortionsreported-in-canada-in-2017

Canadian Institute for Health Information (CIHI). (2018). Induced abortion reported in Canada in 2018 [Data set]. https://www.cihi.ca/en/search?queryall=abortion \&Search + Submit

Canadian Nurses Association (CNA). (2017). Code of ethics for registered nurses. https://www.cna-aiic.ca/html/en/Code-ofEthics-2017-Edition/files/assets/basichtml/page-1.html

Cano, J. K. \& Foster, A. M. (2016). “They made me go through like weeks of appointments and everything": Documenting women's experiences seeking abortion care in Yukon territory, Canada. Contraception, 94(5), 489-495. https://doi.org/10.1016/j.contraception.20 16.06 .015

Carson, A. (2018). Feminism, biomedicine and the 'reproductive destiny' of women in clinical texts on the birth control pill. Culture, Health \& Sexuality, 20(7), 830843. 
The Canadian Journal of Critical Nursing Discourse

See it. Speak it. Write it. Change it.

https://doi.org/10.1080/13691058.2017.13 84852

CBC News. (2018, February 1). Safe zones around abortion clinics now in place. CBC News.

https://www.cbc.ca/news/canada/ottawa/o ttawa-abortion-clinic-safezone-police1.4510607

CBC News. (2019, April 4). Abortion pills replace demand for surgical termination of pregnancy at Victoria Clinic. CBC News.

https://www.cbc.ca/news/canada/britishco $\underline{\text { lumbia/mifegymiso-abortion-pill- }}$ 1.5083852

Clementson, L. (2019, May 9). 'We pledge to make abortion unthinkable in our lifetime': PC MPP Sam Oosterhoff. CBC News.

https://www.cbc.ca/news/canada/hamilton loosterhoff-abortion-1.5129494

Daley, A. E. \& MacDonnell, J. A. (2011). Gender, sexuality and the discursive representation of access and equity in health services literature: Implications for LGBT communities. International Journal for Equity in Health, 10(40), 110. https://doi.org/10.1186/1475-9276-10$\underline{40}$

Deveau, A. (2017). Timeline of a maternal breakdown: A feminist mother's blog post about her abortion experience. In E. R. M. Lind \& A. Deveau (Eds.), Interrogating Pregnancy Loss: Feminist Writings on Abortion, Miscarriage, and Stillbirth (pp. 40-46). Demeter Press.

DiLapi, E. M. (1989). Lesbian mothers and the motherhood hierarchy. Journal of Homosexuality, 18(1-2), 101-121. https://doi.org/10.1300/J082v18n01_05

Dressler, J., Maughn, N., Soon, J. A., \& Norman, W. V. (2013). The perspective of rural physicians providing abortion in Canada: Qualitative findings of the BC Abortion Providers Survey (BCAPS). PLOS ONE, 8(6), 1-5. https://doi.org/10.1371/journal.pone.0067 070

Eaton, A. (2018 Sep 15). Graphic anti-abortion protests have no place on campus. The Varsity. https://thevarsity.ca/2018/09/15/op-edgraphic-anti-abortion-protests-have-noplace-on-campus/

Ehrenreich, B., \& English, D. (2010). Witches, midwives, \& nurses: A history of women healers $\left(2^{\text {nd }}\right.$ ed.). Feminist Press. (Original work published 1973)

Endemann, E. (2019, April 25). Anti-abortion ad on Ottawa bus angers two councillors.

Ottawa Citizen.

https://ottawacitizen.com/news/localnews/anti-abortion-ad-onottawa-busangers-two-councillors

Fairclough, N. (1995). Critical discourse analysis: The critical study of language. Longman.

Foster, A. M, LaRoche, K. J., El-Haddad, J., DeGroot, L. \& El-Mowafi, I. M. (2017). "If I ever did have a daughter, I wouldn't raise her in New Brunswick:" Exploring women's experiences obtaining abortion care before and after policy reform.

Contraception, 95(5), 477-484.

https://doi.org/10.1016/j.contraception.20 17.02 .016

Ganatra, B., Gerdts C., Rossier C., Ronald Johnson Jr., B., Tunçalp, Ö., Assifi, A., Sedgh, G., Singh, S., Bankole, A., Popinchalk, A., Bearak, J., Kang, Z., \& Alkema, L. (2017). Global, regional, and subregional classification of abortions by safety, 2010-14: Estimates from a Bayesian hierarchical model. The Lancet, 390(10110), 2372-2381. https://doi.org/10.1016/S01406736(17)31794-4

Greaves, L., \& Whynot, E. (2014). Promoting women's hospitals as a site for change. In L. Greaves, A. Pederson, \& N. Poole (Eds.), Making it better: Gender- 
The Canadian Journal of Critical Nursing Discourse

See it. Speak it. Write it. Change it.

transformative health promotion (pp.

225-239).

Green, F. J. (2018). Empowering mothers and daughters through matroreform and feminist motherliness. Journal of the Motherhood Initiative, 9(1), 9-20. https://jarm.journals.yorku.ca/index.php/ja $\mathrm{rm} /$ article/view/40475\%20

Green, F. J. (2019). Practicing matricentric feminist mothering. Journal of the Motherhood Initiative, 10(1\&2), 83-99. https://jarm.journals.yorku.ca/index.php/ja $\underline{\mathrm{rm} / \mathrm{article} / \mathrm{view} / 40555}$

Hankivsky, O. (2007). More than age and biology: Overhauling lifespan approaches to women's health. In M. Morrow, O. Hankivsky, \& C. Varcoe (Eds.), Women's health in Canada: Critical perspectives on theory and policy (pp. 64-90). University of Toronto Press.

Hankivsky, O. (2020). Using intersectionality to understand who is most at risk for COVID-19. Pursuit.

https://pursuit.unimelb.edu.au/articles/usi ng-intersectionality-to-understand-who-ismost-at-risk-of-covid-19

Ibrahim, H. (2018, July 31). Anti-abortion centre reopens next door to Clinic 554. CBC News. https://www.cbc.ca/news/canada/newbrunswick/right-to-life-clinic554abortion-1.4768481

Janiak, E., \& Goldberg, A. B. (2016). Eliminating the phrase "elective abortion": Why language matters. Contraception, 93(2), 89-92. https://doi.org/10.1016/j.contraception.20 15.10 .008

Jones, R. K., Frohwirth, L. F., \& Moore, A. M. (2008). "I would want to give my child, like everything in the world". Journal of Family Issues, 29(1), 79-99. https://doi.org/10.1177/0192513X073057 $\underline{53}$
Kagan, P. N., Smith, M. C., Richard Cowling III, W., Chinn, P. L. (2010). A nursing manifesto: an emancipatory call for knowledge development, conscience, and praxis. Nursing Philosophy, 11, 67-84. https://doi.org/10.1111/j.1466769X.2009.00422.X

Kagan, P. N., Smith, M. C., \& Chinn, P. L. (2014). Introduction. In P. N. Kagan, M. C. Smith \& P. L. Chinn (Eds.), Philosophies and Practices of Emancipatory Nursing: Social Justice as Praxis (pp. 1-17). Routledge.

Kaposy, C. (2009). The public funding of abortion in Canada: Going beyond the concept of medical necessity. Medicine, Health Care, and Philosophy, 12(3), 301311. https://doi.org/10.1007/s11019-0089164-9

Lazar, M. (2007). Feminist critical discourse analysis: Articulating a feminist discourse praxis. Critical Discourse Studies, 4(2), 141-164.

https://doi.org/10.1080/174059007014648 16

Lippman, A. (2014). Foreward. In S. Patterson, F. Scala \& M. K. Sokolon (Eds.), Fertile ground (pp. xiii-xv). McGill-Queen's University Press.

Lowik, A. J. (2018). Trans-inclusive abortion services: A manual for providers on operationalizing trans-inclusive policies and practices in an abortion setting. http://www.fqpn.qc.ca/main/wpcontent/uploads/2017/12/FQPN-ManualEN-Web.pdf

MacDonnell, J. (2006). Exploring matrices of mothering and feminisms: Understanding mothering discourses for lesbian health advocates through life histories. Journal of the Association for Research on Mothering, 8(1, 2), 298-310. https://jarm.journals.yorku.ca/index.php/ja $\mathrm{rm} /$ article/view/5034 
MacDonnell, J. (2014). Enhancing our understanding of emancipatory nursing: A reflection on the use of critical feminist methodologies. Advances in Nursing Science, 37(3), 271-280. https://doi.org/10.1097/ANS.0000000000 000038

Mallick, H. (2017, January 13). After antiabortion ads on buses, what's next?: Mallick. The Toronto Star. https://www.thestar.com/news/gta/2017/0 1/13/after-antiabortion-ads-on-buseswhats-next-mallick.html

McIntyre, M., Anderson, B., \& McDonald, C. (2001). The intersection of relational and cultural narratives: Women's abortion experiences. Canadian Journal of Nursing Research, 33(3), 47-62.

McPherson, K. (2003). Bedside Matters: The transformation of Canadian nursing, 1900-1990. Oxford University Press.

Medoff, M. (2016). Pro-choice versus pro-life: The relationship between state abortion policy and child well-being in the United States. Health Care for Women International, 37(2), 158-169. https://doi.org/10.1080/07399332.2013.84 1699

Mitchell, K. (2019). "It was everyone's judgement": Experiences seeking abortion in Southern Alberta (2007-2017).

[Master's thesis, University of Lethbridge]. University of Lethbridge Research Repository. https://opus.uleth.ca/bitstream/handle/101 33/5411/MITCHELL_KATELYN_MA_2 019.pdf? sequence $=3$

National Abortion Federation. (2020). Clinical Policy Guidelines for Abortion Care. https://5aa1b2xfmfh2e2mk03kk8rsxwpengine.netdna-ssl.com/wpcontent/uploads/2020_cpgs_final.pdf

Norman, W. V., Soon, J. A., Maughn, N. \& Dressler, J. (2013). Barriers to rural induced abortion services in Canada:
Findings of the British Columbia Abortion Providers Survey. PloS ONE, 8(6), e67023.

https://doi.org/10.1371/journal.pone.0067 $\underline{023}$

O'Reilly, A. (2004). Introduction. In A. O'Reilly (Ed.), Mother matters: Motherhood as discourse and practice (pp.11-26). Association for Research on Mothering. Paynter, M., Norman, W. \& Martin-Misener, R. (2019). Nurses are key members of the abortion care team: Why aren't schools of nursing teaching abortion care? Witness:

The Journal of Critical Nursing Discourse, 1(2), 17-29. https://doi.org/10.25071/2291-5796.30

Pederson, A., Poole, N., Greaves, L., Gerbrandt, J., \& Fang, M. L. (2014). Envisioning gender-transformative health promotion. In L. Greaves, A. Pederson, \& N. Poole (Eds.), Making It Better: GenderTransformative Health Promotion (pp. 17-41). Canadian Scholars' Press/Women's Press.

Peters, J. W. (2020, April 20). How abortion, guns and church closings made Coronavirus a culture war in America. New York Times.

https://www.nytimes.com/2020/04/20/us/ politics/coronavirus-protests-democratsrepublicans.html

Purcell, C. (2015). The sociology of women's abortion experiences: Recent research and future directions. Sociology Compass, 9(7), 585-596.

https://doi.org/10.1111/soc4.12275

Rippeyoung, P. L. F. (2013). Governing motherhood: Who pays and who profits? Canadian Centre for Policy Alternatives. https://www.policyalternatives.ca/sites/def ault/files/uploads/publications/reports/doc s/Governing\%20Motherhood.pdf

Ross, L. \& Solinger, R. (2017). Reproductive Justice: An introduction. University of California Press. 
Saurette, P. \& Gordon, K. (2013). Arguing abortion: The new anti-abortion discourse in Canada. Canadian Journal of Political Science, 46(1), 157-185. https://doi.org/10.1017/S00084239130001 $\underline{76}$

Saurette, P. \& Gordon, K. (2015). The changing voice of the anti-abortion movement: The rise of "pro-woman" rhetoric in Canada and the United States. University of Toronto Press.

Sethna, C. \& Doull, M. (2013). Spatial disparities and travel to freestanding abortion clinics in Canada. Women's Studies International Forum, 38(Complete), 52-62. https://doi.org/10.1016/j.wsif.2013.02.001

Smith, J. L. (2007). Critical discourse analysis for nursing research. Nursing Inquiry, 14(1), 60-70.

https://doi.org/10.1111/j.14401800.2007.00355.X

Stettner, S. (2016a). A brief history of abortion in Canada. In S. Stettner (Ed.), Without apology: Writings on abortion in Canada (pp. 31-76). AU Press Athabasca University.

https://www.aupress.ca/app/uploads/1202 57_99Z_Stettner_2016Without_Apology.pdf

Stettner, S. (2016b). Without apology: An introduction. In S. Stettner (Ed.), Without apology: Writings on abortion in Canada (pp. 3-30). AU Press Athabasca University. https://www.aupress.ca/app/uploads/1202 57 99Z Stettner 2016Without_Apology.pdf

Traynor, M. (2017). Critical resilience for nurses: An evidence-based guide to survival and change in the modern NHS. Routledge.

Vogel, L. (2012). Sex-selective abortions: No simple solution. CMAJ, 184(3), 286-288. https://doi.org/10.1503/cmaj.109-4097

Vogel, K., LaRoche, K. J., El-Haddad, J., Chaumont, A., \& Foster, A. M. (2016).
Exploring Canadian women's knowledge of and interest in mifepristone: results from a national qualitative study with abortion patients. Contraception, 94, $137-$ 142.

https://doi.org/10.1016/j.contraception.20 16.04 .008

Weitz, T. A. (2010). Rethinking the mantra that abortions should be 'safe, legal, and rare'. Journal of Women's History, 22(3), 161172.

https://doi.org/10.1353.jowh.2010.0595

Wiebe, E., Najafi, R., Soheil, N., Kamani, A. (2011). Muslim women having abortions in Canada: Attitudes, beliefs, and experiences. Canadian Family Physician, 57, e134-138.

Wiebe, E., Chalmers, A., \& Yager, H. (2012). Delayed motherhood: Understanding the experiences of women older than age 33 who are having abortions but plan to become mothers later. Canadian Family Physician, 58, e588-95.

Winnikoff, B., \& Sheldon, W. (2012). Use of medicines changing the face of abortion. International Perspectives on Sexual and Reproductive Health, 38(3), 164-166. https://www.guttmacher.org/journals/ipsrh 12012/09/use-medicines-changing-faceabortion

World Health Organization. (2018, Feb 19). Preventing Unsafe Abortion. https://www.who.int/en/news-room/factsheets/detail/preventing-unsafe-abortion

Yasseen III, A. S. \& Lacaze-Masmonteil, T. (2016). Male-biased infant sex ratios and patterns of induced abortion. CMAJ, 188(9), 640-641. https://doi.org/10.1503/cmaj.160183

Zingel, A. (2019, April 25). Removal of ultrasound requirement could improve access in remote communities to abortion drug. CBC News. https://www.cbc.ca/news/canada/north/ab ortion-pill-ultrasound-access-1.5110044 